\title{
Meta
}

Journal des traducteurs

Translators' Journal

\section{CRÉPEAU, Paul-A. et al. (1991) : Dictionnaire de droit privé et Lexiques bilingues, Deuxième édition, Cowansville (Québec), Les Éditions Yvon Blais inc., 741 p.}

\section{Wallace Schwab}

Volume 38, numéro 3, septembre 1993

URI : https://id.erudit.org/iderudit/004069ar

DOI : https://doi.org/10.7202/004069ar

Aller au sommaire du numéro

Éditeur(s)

Les Presses de l'Université de Montréal

ISSN

0026-0452 (imprimé)

1492-1421 (numérique)

Découvrir la revue

Citer ce compte rendu

Schwab, W. (1993). Compte rendu de [CRÉPEAU, Paul-A. et al. (1991) :

Dictionnaire de droit privé et Lexiques bilingues, Deuxième édition, Cowansville

(Québec), Les Éditions Yvon Blais inc., 741 p.] Meta, 38(3), 542-543.

https://doi.org/10.7202/004069ar d'utilisation que vous pouvez consulter en ligne.

https://apropos.erudit.org/fr/usagers/politique-dutilisation/ 
CRÉPEAU, Paul-A. et al. (1991): Dictionnaire de droit privé et Lexiques bilingues, Deuxième édition, Cowansville (Québec), Les Éditions Yvon Blais inc., 741 p.

Le titre du Dictionnaire de droit privé cache en fait un vaste projet - véritable fresque lexicale du droit québécois - visant bien au-delà des 4000 acceptions se trouvant dans cette deuxième édition. Le directeur, P.-A. Crépeau, s'exprime en ces termes: «Comme il s'agit d'une œuvre de longue haleine - l'ouvrage, une fois complété, comprendra environ 10000 termes -, il a paru utile de publier le dictionnaire par versions cumulatives». Donc, la présente édition est, au même titre que la précédente, un rapport d'étape. En procédant ainsi, le professeur Crépeau a sans doute vu très juste, surtout lorsque l'on considère l'ampleur de la besogne que son équipe du Centre de recherche en droit privé et comparé du Québec s'est attelée à abattre.

L'ouvrage est divisé en trois parties: le dictionnaire, le lexique anglais-français et la liste des auteurs et des ouvrages cités.

De loin, la partie dictionnaire constitue l'élément le plus accrocheur puisqu'elle met à la disposition des usagers de la langue un instrument de travail de bonne souche québécoise, par ailleurs introuvable. Chaque entrée au dictionnaire est conforme à une présentation uniforme, soit le terme-vedette suivi d'un article définitoire comportant de nombreux éléments d'information: la catégorie grammaticale, la langue d'origine, un numéro d'acception, le domaine d'emploi, la mention d'usage, la définition et d'autres accessoires comme une illustration juridique, une citation, un exemple linguistique, l'occurrence, une remarque, et s'il y a lieu, un terme synonyme, un terme opposé, un terme voisin ou une forme fautive. Chaque article se termine par un bloc lexique présentant le ou les équivalents en langue anglaise.

Pour le juriste qui dépend tant de l'emploi précis de la langue, cette présentation rigoureuse ne manquera pas de le rendre encore plus exigeant quant à l'utilisation de sa langue française.

En ce qui a trait à la teneur des entrées, voici la description des auteurs (p. XXII) : «Ouvrage de spécialité, le Dictionnaire ne comprend pas, en principe, de termes relevant de la langue courante, à moins qu'ils n'aient aussi une acception juridique, comme ACTE et OBLIGATION. Il ne donne pas non plus le sens courant de termes juridiques, sauf pour éviter une confusion possible ou en raison d'un emploi fréquent dans un texte législatif.»

Dans la grande majorité des entrées, on s'inspire de nombreuses citations puisées dans la doctrine. De même, les références aux lois y sont tout aussi fréquentes, ce qui ajoute encore à la valeur de l'ouvrage. 
En comparaison avec l'édition précédente, on remarque la présence d'un plus grand nombre de domaines et on lit dans la présentation du dictionnaire que les «définitions portent sur les généralités du droit et sur l'ensemble du droit des obligations, du droit des biens et des sûretés, de la prescription et du droit international privé. Le droit des personnes et des successions, le droit judiciaire privé et le droit commercial sont définis en partie».

Les utilisateurs anglophones ne manqueront pas de remarquer nombre d'innovations néologiques qui ne les laisseront certainement pas indifférents. Le recours aux néologismes s'avère un enjeu risqué, mais nécessaire dans le contexte du présent dictionnaire. Toutefois, l'emploi de termes n'ayant pas encore reçu l'attestation des usages législatifs et populaires pourrait entraîner une certaine confusion lexicale, voire insécurité linguistique, surtout si à long terme certains de ces termes se trouvaient rejetés par la communauté anglophone de juristes civilistes. Par contre, je n'ai pas de mal à m'imaginer la satisfaction des civilistes francophones devant des équivalents anglais tels «creance, creancer, prestation, resiliation, resolution» (pour les retraduire en français, ajoutez les accents aux bons endroits et vous y êtes). Je doute que leurs homologues de langue anglaise soient aussi enchantés. Mais, il est inutile à ce stade de porter un jugement sur le bien-fondé du processus; avec le temps, l'usage s'en chargera.

La présente «livraison» rendra certainement service aux praticiens, aux rédacteurs et aux traducteurs, tout comme la précédente. En outre, son emploi chez l'utilisateur québécois permettra un sevrage des dictionnaires étrangers - bien que d'excellente frappe dans la plupart des cas - qui ont pour effet de renseigner sur des réalités d'ailleurs sans jamais cerner le droit dont nous avons surtout besoin.

Donc, dans l'attente de la prochaine tranche, félicitations une fois de plus au professeur Crépeau et à son équipe.

WaLlace SCHWAB 